\title{
PUBERTY IN THE WELSH STALLION
}

\author{
J. D. SKINNER AND J. BOWEN \\ A.R.C. Unit of Reproductive Physiology and Biochemistry, * Cambridge
}

(Received 8th December 1967)

Relatively little is known about the time when the stallion reaches puberty. In the Anglo-Norman breed the testes have been shown to increase gradually in weight from the 11th month onwards, and then more rapidly from the 16th month (Nishikawa \& Horie, 1955). Large amounts of testosterone have been found in the spermatic vein blood of mature stallions (Lindner, 1959, 1961). It has also been postulated that the rise in urinary oestrogen excretion accompanies sexual maturation at 20 months (Zondek, 1934; Pigon, Lunaas \& Velle, 1961). The object of the present experiment was to study sexual development in living pony stallions from birth until the time when spermatozoa appear in ejaculates, and to define the time relationship between the onset of androgenic and gametogenic testicular functions. In addition, a study was made of the effects of season on puberty and semen composition.

Material was provided by four Welsh stallions made available from the Unit's own herd. Three were available from birth and the fourth from the age of 15 months onwards. The foals were weaned at 6 months and clinically examined at 9 months of age (mid-winter) when the testes were very small and male behaviour was not evident. Six weeks later, with lengthening daylight, the testes were already larger and male behaviour, including masturbation, became apparent. This agrees with previous observations on the behaviour of young stallions (Hafez, Williams \& Wierzbowski, 1962). The stallions were now trained to mount a teaser mare, constantly in oestrus, and ejaculate into an artificial vagina (Walton, 1938). Semen was collected at weekly intervals from the younger stallions until spermatozoa appeared in the ejaculate and from the older stallion from 15 to 27 months of age. The following were determined: volume of semen (seminal gel, if present, was included); sperm density in a haemocytometer; citric acid (Mann, 1964), and also time interval between entry of the stallion into the 'teaser' paddock and ejaculation (reaction time). The main results from the older stallion are illustrated in Text-fig. 1.

In the three younger stallions ejaculate volume and citric acid concentration increased steadily, from $5 \mathrm{ml}$ and $2 \mathrm{mg} / 100 \mathrm{ml}$ at the first attempt to $9 \mathrm{ml}$ and $4 \mathrm{mg} / 100 \mathrm{ml} 4$ weeks later and $18 \mathrm{ml}$ and $14 \mathrm{mg} / 100 \mathrm{ml} 12$ weeks later, respectively. Reaction time was protracted at first after which a pattern developed in each animal. Reaction time became shorter as the citric acid concentration increased.

The young stallions commenced ejaculating into the artificial vagina 4,14 and 14 weeks, respectively, before the appearance of spermatozoa in

* Postal address: Animal Research Station, 307 Huntingdon Road, Cambridge. 
the ejaculate. The duration of the spermatogenic cycle in the stallion is, to our knowledge, unknown, but it seems unlikely that it would differ significantly from the duration in other mammals, and take longer than 10 weeks. It would appear, therefore, that, as in other species, androgen secretion precedes spermatogenesis. The motility of the first spermatozoa was not good, extremely few showing any progressive movement. The mean age at appearance of spermatozoa was 13 months (11.5 to 14.5 months) and in close agreement with the findings of Horie \& Nishikawa (1955) in the Anglo-Norman breed. The mean weight of the stallions was $180 \mathrm{~kg}$ (range 160 to $210 \mathrm{~kg}$ ) at this stage.
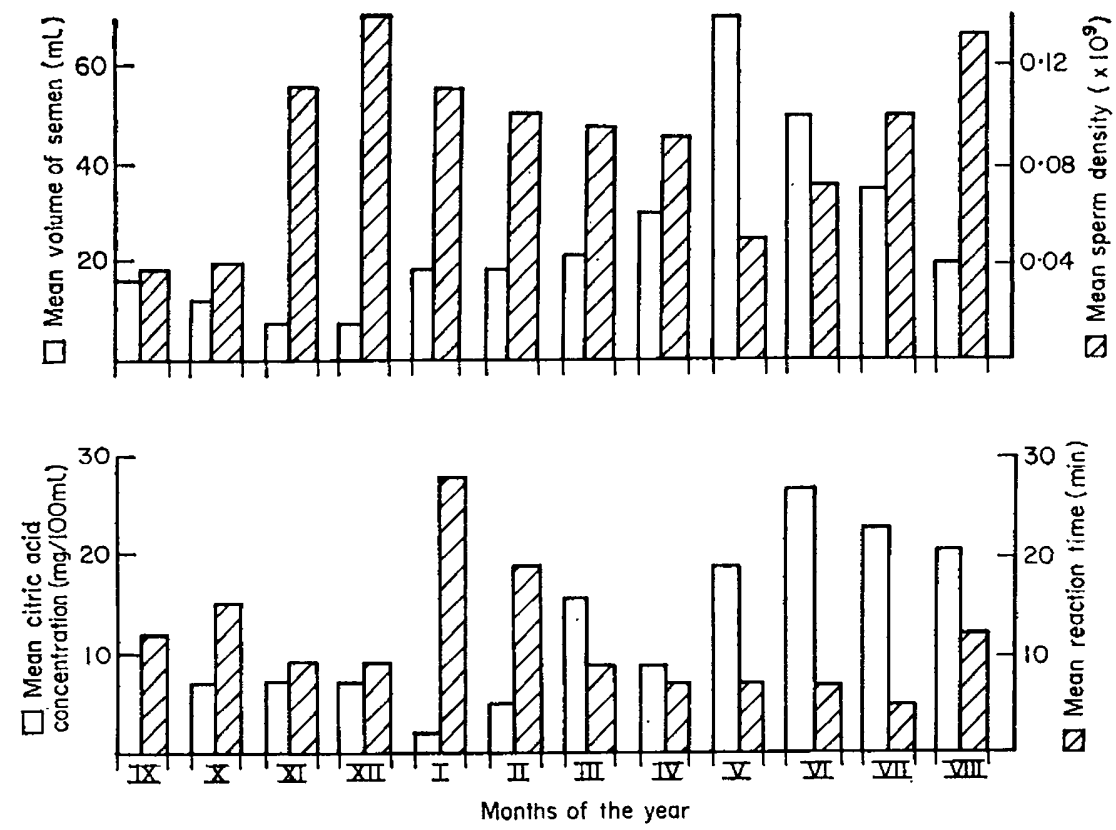

Text-Fig. 1. The mean weekly output of semen, spermatozoa density, citric acid concentration and reaction time each month in a stallion, 15 months old at the commencement of the experiment.

Collections commenced from the older stallion with the approach of autumn. As daylight shortened, reaction time lengthened and ejaculate volume and citric acid content declined. The concentration of spermatozoa and their motility, both of which were variable, were, however, improving. As daylight lengthened in the spring, reaction time decreased, ejaculate volume and citric acid content and, in particular, the amount of gel increased. The spermatozoa concentration and their motility declined, possibly as a result of these changes, but also due to an increased tendency to agglutinate when large amounts of gel were present. The response of the stallion to increasing daylight is well known (Lintvareva, 1955; Mann, Leone \& Polge, 1956), and it is, therefore, not surprising that these results are in agreement.

When the gel, which originates in the seminal vesicle, was assayed separately, it contained $60 \mathrm{mg} / 100 \mathrm{ml}$ of citric acid while the remainder of the ejaculate, presumably also containing some gel, contained only $20 \mathrm{mg} / 100 \mathrm{ml}$ of citric 
acid. This confirms the findings of Mann et al. (1956) that the gel is the major source of citric acid in the stallion.

There is a correlation between citric acid content and androgen activity (Humphrey \& Mann, 1948, 1949; Mann \& Parsons, 1950), and it behaves similarly to seminal fructose in other species following castration. It would, therefore, appear that androgen secretion in the stallion is strongly influenced by daylight length, whereas spermatogenesis is not influenced to any noticeable extent.

Within the limitations of this experiment, it would appear that testicular growth rate increases after the first winter when androgen secretion increases. Due to the shorter hours of daylight, puberty can only commence after the first winter when the stallion begins to display masculine behaviour and secretes increasing amounts of androgen. Androgenic activity is again retarded during the second winter period, after which the stallion can attain its inherent potential sexual function. This second rise in androgen output would coincide with the rise in urinary oestrogens reported by other workers (Zondek, 1934; Pigon et al., 1961).

We would like to thank Professor T. Mann and Mr L. E. A. Rowson for their advice and interest in this work. One of us (J.D.S.) is indebted for a scholarship to British Petroleum (Southern Africa).

\section{REFERENCES}

Hafez, E. S. E., Williams, M. \& Wierzbowskr, S. (1962) The behaviour of horses. In: The Behaviour of Domestic Animals, Chap. 13. Ed. E. S. E. Hafez. Baillière, Tindall \& Cox, London.

Horie, T. \& Nishikawa, Y. (1955) Studies on the development of the testis and epididymis of the horse. II. The development of the epididymis and the properties of the sperm collected from the epididymis. Bull. natn. Inst. agric. Sci., Tokyo, Ser. G, 10,351.

Humphrey, G. F. \& MANN, T. (1948) Citric acid in semen. Nature, Lond. 161, 352.

Humphrey, G. F. \& ManN, T. (1949) Studies on the metabolism of semen. 5. Citric acid in semen. Biochem. 7. 44, 97.

LindNer, H. R. (1959) Androgens in the bovine testis and spermatic vein blood. Nature, Lond. 183, 1605.

LiNDNER, H. R. (1961) Testicular androgen in the ram, boar and stallion. F. Endocr. 23, 171.

Lintvareva, N. I. (1955) The effect of light on reproduction. Trudy uses. Nauchno-issled. Inst. Konev. p. 45. Anim. Breed. Abstr. 24, 1491.

ManN, T. (1964) Biochemistry of semen and of the male reproductive tract, 2nd edn. Methuen, London.

Mann, T., Leone, E. \& Polge, C. (1956) The composition of stallion's semen. F. Endocr, 13, 279.

Mann, T. \& Parsons, U. (1950) Studies on the metabolism of semen. 6. Role of hormones. Effect of castration, hypophysectomy and diabetes. Relation between blood glucose and seminal fructose. Biochem. 7. 46, 440.

Nishikawa, Y. \& Horie, T. (1955) Studies on the development of the testes and epididymides of the horse. I. Studies on the development of the testes of the horse, with special reference to singularity and the age of sexual maturity. Bull. natn. Inst. agric. Sci., Tokyo, Ser. G, 10, 299.

Pigon, H., Lunaas, T. \& Velle, W. (1961) Urinary oestrogens in the stallion. Acta endocr., Copenh. $36,131$.

Walton, A. (1938) Artificial insemination of sheep, cattle and horses, 2nd edn. Holborn Surgical Instrument Co., London.

Zondex, B. (1934) Oestrogenic hormone in the urine of the stallion. Nature, Lond. 133, 494. 